\title{
Editorial: Physical Review Fluids: The First Year and Beyond
}

Physical Review Fluids (PR Fluids) was launched in January 2016. It started accepting submissions a month later and its first issue was published in May 2016. As of now, we have received over 700 submissions (including 75 Rapid Communications), with approximately 280 papers accepted and in most cases already published. We are pleased to announce that the journal has now been indexed by the Science Citation Index (SCI), and we anticipate receiving the first impact factor after the second anniversary of publication.

The first volume far exceeded our original expectations both in terms of quality and scope. Its papers range from fundamental fluid physics to applied fluid mechanics related to energy creation and harvesting, through biology, forensic science, and understanding of climate changes, all the way to the implications of landing on Mars. We have made a great start and believe that we are well on the way to becoming the best and most interesting fluid dynamics journal.

In achieving this we have benefited greatly from the support of and collaboration with the American Physical Society's Division of Fluid Dynamics (DFD), including the publication of invited papers and of the Gallery of Fluid Motion from the 2015 DFD annual meeting. Starting in 2017, the François Frenkiel Award of the DFD will be awarded for the best paper by authors under the age of 40 published in PR Fluids.

PR Fluids encourages the submission of fundamentally oriented theoretical or experimental manuscripts. We publish both regular papers as well as shorter Rapid Communications for Letter style papers of special significance. Although the traditional topics of fluid dynamics comprise a main focus of PR Fluids, we encourage the submission of papers in newer and emerging areas, including bio-related fluid dynamics, micro- and nanoscale flows, fluid mechanics of complex fluids and soft materials, and geo- and environmental flows.

PR Fluids offers rapid editorial processing by a first-class editorial team, combined with the wide visibility associated with being a member of the APS Physical Review family of journals.

John Kim

Gary Leal

Editors

Published 31 January 2017

DOI: 10.1103/PhysRevFluids.2.010001 